\title{
PREPARATION OF SILVER AND COPPER NANOPARTICLES IN PRESENCE OF ASCORBIC ACID AND INVESTIGATION OF THEIR ANTIBACTERIAL ACTIVITY
}

\author{
BOJANA LABAN ${ }^{*}$, MILENA KOŠANIN ${ }^{1}$, GORAN ISIĆ ${ }^{2}$, UROŠ RALEVIĆ ${ }^{2}$, MIRIJANA \\ MARKOVIĆ ${ }^{3}$, ANJA JOKIĆ ${ }^{1}$, VESNA VASIĆ \\ ${ }^{1}$ Faculty of Natural Science and Mathematics, University of Priština, Kosovska Mitrovica, Serbia \\ ${ }^{2}$ Graphene Laboratory of Center for Solid State Physics and New Materials, Institute of Physics Belgrade, University of \\ Belgrade, Belgrade, Serbia \\ ${ }^{3}$ Vinča Institute of Nuclear Sciences, University of Belgrade, Belgrade, Serbia
}

\begin{abstract}
In this study, we present a synthesis of silver and copper nanoparticles (NPs) using ascorbic acid as stabilizing and sodium borohydride as reducing agents, respectively. Four colloidal dispersions were obtained, two of them additionally stabilized by gelatin. They were characterized by UV-Vis, AFM, DLS and zeta potential measurements. The size of both silver and copper NPs, determined by AFM measurements, was $10 \mathrm{~nm}$ before, and $15 \mathrm{~nm}$ after stabilization with gelatin. Antibacterial activity of synthesized NPs was tested using series of gram positive and gram negative bacteria. It was found that $\mathrm{Ag}$ and $\mathrm{Cu}$ NPs showed antibacterial activity in all cases.
\end{abstract}

Keywords: Silver nanoparticles, copper nanoparticles, antibacterial activity.

\section{INTRODUCTION}

Metal nanoparticles (NPs) are the subject of interest for many researchers, among all because of their unique optical properties (Mulvaney, 1996; Daniel \& Astruc, 2004; Kelly et al., 2003; Sosa et al., 2003.; Austin et al., 2014). Because of their electronic properties and large surface area, they possess different physical and chemical properties in comparison to bulk materials. It is well known that metal NPs, due to the excitation of localized surface plasmon resonance, possess unique optical properties in the visible range (Mulvaney, 1996). They have found applications in many different areas such as catalysis (Yacamán et al., 2001; Zhang et al., 2013), electronics (Li et al., 2005), optical sensing (Wang et al., 2012; Li et al., 2015) and biosensing (Walcarius et al., 2013). Numerous publications for synthesis of silver (Maria et al., 2013; Dong et al., 2009; Hu et al., 2004; Zhang et al., 2011; Mahmoud et al., 2012; Qin et al., 2010; Chekin \& Ghasemi, 2014) and copper (Salavati-Niasari \& Davar, 2009; Youngil et al., 2008; Zhu et al., 2005; Ramyadevi et al., 2012; Zain et al., 2014; Valodkar et al., 2011) colloids have been reported, and the most frequently used method is a chemical reduction of their ions, whereas various reducing and stabilizing agents were used. So far it has been reported the use of ascorbic acid as a reducing agent for metal NPs synthesis by using microwave irradiation (Qin et al., 2010; Chekin and Ghasemi, 2014).

Silver NPs are of interest because of their antibacterial activity and localized surface plasmon resonance properties (Song et al., 2013; Panáček et al., 2006; Amendola et al., 2010;
Mogensen \& Kneipp, 2014). Developing the route of synthesis enabled the control of desired size, shape, and capping agents.

Copper NPs are attractive because of the high natural abundance of $\mathrm{Cu}$ and low cost, also there are multiple ways of preparing $\mathrm{Cu}$-based nanomaterials. The interest for $\mathrm{Cu}$ NPs is due to their possible electrocatalytic and antimicrobial application as well as in biosensing (Zain et al., 2014; Valodkar et al., 2011; Ehsani et al., 2014; Lu et al., 2012; Wang et al., 2004).

In this study, we report the preparation of silver and copper NPs in aqueous solutions by chemical reduction method, and their antibacterial activity. In order to obtain the small size particles, we used sodium borohydride as a reducing agent and ascorbic acid as a stabilizing agent. Since ascorbic acid is not a strong stabilizer agent, the colloidal dispersion was additionally stabilized by gelatin. UV-Vis spectroscopy and zeta potential measurements were used for characterization of $\mathrm{Ag}$ and $\mathrm{Cu}$ colloids, while microscopic method Atomic Force Microscopy (AFM) and optical method Dynamic Light Scattering (DLS) were used in particle size characterization (Chicea, 2014; Klapetek et al., 2011; Hoo et al., 2008).

Lately, the interest in the application of NPs as antimicrobial agents increased because of the growing bacterial resistance to antibiotics (Zain et al., 2014; Valodkar et al., 2011). Synthesized silver and copper NPs were used to examine their antibacterial activity against gram-negative bacteria Acinetobacter, Escherichia Coli, Pseudomonas aeruginosa and Klebsiella pneumoniae, and against gram-positive bacteria Enterococcus faecium.

\footnotetext{
* Corresponding author: bojana.laban@pr.ac.rs 


\section{EXPERIMENTAL}

\section{Materials}

Silver nitrate $\left(\mathrm{AgNO}_{3}\right)$, Copper (II) nitrate $\left(\mathrm{Cu}\left(\mathrm{NO}_{3}\right)_{2}\right)$, ascorbic acid $\left(\mathrm{C}_{6} \mathrm{H}_{8} \mathrm{O}_{6}\right)$, sodium borohydride $\left(\mathrm{NaBH}_{4}\right)$ and gelatin from bovine skin were of analytical grade and purchased from Aldrich or Merck. Purified Millipore Mili-Q water with a resistivity of $18 \mathrm{M} \Omega$ was used in all cases.

\section{Synthesis}

\section{Synthesis of silver nanoparticles}

For the synthesis of silver nanoparticles, silver nitrate was used as a precursor and ascorbic acid as a stabilizing agent. 100 $\mathrm{ml}$ of $10^{-4} \mathrm{M} \mathrm{AgNO}_{3}$ was containing $2.5 \times 10^{-5} \mathrm{M}$ of ascorbic acid, and then $10 \mathrm{mg}$ of $\mathrm{NaBH}_{4}$ was added at room temperature. The transparent colorless solution becomes pale yellow indicating the formation of silver nanoparticles. The colloidal dispersion prepared in this way remains stable for few hours at room temperature and up to $24 \mathrm{~h}$ in the fridge at $5^{\circ} \mathrm{C}$. In order to keep the silver colloidal dispersion stable for a longer period of time, $1 \mathrm{ml}$ of $1 \%$ gelatin was added. That way dispersion remains stable for few months.

\section{Synthesis of copper nanoparticles}

The copper colloidal dispersion was prepared using copper (II) nitrate as a precursor and ascorbic acid as a stabilising agent. In $100 \mathrm{ml}$ of a solution containing $5 \times 10^{-4} \mathrm{M} \mathrm{Cu}\left(\mathrm{NO}_{3}\right)_{2}$ and 1.25 $\times 10^{-4} \mathrm{M}$ ascorbic acid, $50 \mathrm{mg}$ of $\mathrm{NaBH}_{4}$ was added at room temperature. The Color became brownish-red, indicating the formation of copper nanoparticles, and the dispersion remained stable $4-5 \mathrm{~h}$ at room temperature. By the addition of $1 \%$ gelatin, the copper colloidal dispersion can be stabilized up to $48 \mathrm{~h}$.

Microbiological method for determining the antibacterial activity of colloidal dispersions

Antibacterial activity of the silver and copper colloids were examined with both gram-positive and gram-negative bacteria as per the below-mentioned procedure. The bacterial strains were isolated from patients and streaked onto Tryptone Soy Agar and incubated overnight at $37^{\circ} \mathrm{C}$. That way prepared bacterial suspension was applied on the surface of a nutrient agar plate. Then, colloidal dispersion of silver and copper was injected, separately, along with control and incubated at $37{ }^{\circ} \mathrm{C}$ for $24 \mathrm{~h}$.

\section{Apparatus}

Absorption spectra of colloidal dispersions were measured by Perkin Elmer Lambda 35 UV - Vis spectrophotometer using the quartz cuvette with $1 \mathrm{~cm}$ path length.

Particle size determination by DLS and zeta potential (ZP), mobility and conductivity measurements by laser Doppler electrophoresis (LDE) were performed using a Zeta-sizer Nano ZS with $633 \mathrm{~nm} \mathrm{He-Ne} \mathrm{laser} \mathrm{(Malvern} \mathrm{Instruments,} \mathrm{UK).} \mathrm{Data}$ were analyzed by the Zetasizer Software Version 6.20 (Malvern Instruments, UK).

Atomic Force Microscopy (AFM) measurements were performed in air (at room temperature), providing spatially resolved chemical information of the sample along with its surface topography at the same place. The experiments were performed using commercial NTegra Spectra system from NTMDT.

\section{RESULTS}

\section{Absorption spectra}

The absorption spectra of Ag colloidal dispersion containing $1 \times 10^{-4} \mathrm{M} \mathrm{Ag}$ ions in the absence and presence of 1 $\%$ gelatin are presented in Fig. 1. As can be seen from Fig. 1, silver colloidal dispersion has intense absorption band, due to the surface plasmon resonance, with a maximum at $387 \mathrm{~nm}$. The shape of the absorption band suggests that Ag NPs are spherical (Laban et al., 2013; Laban et al., 2014; Laban et al., 2015; Laban et al., 2016). The presence of gelatin (Fig. 1 b) induced the broadening of the absorption band and red shifting of the maximum for $10 \mathrm{~nm}$ (absorption maximum at $397 \mathrm{~nm}$ ), due to the change of surrounding media as well as a possible agglomeration of the certain number of NPs (Laban et al., 2014).

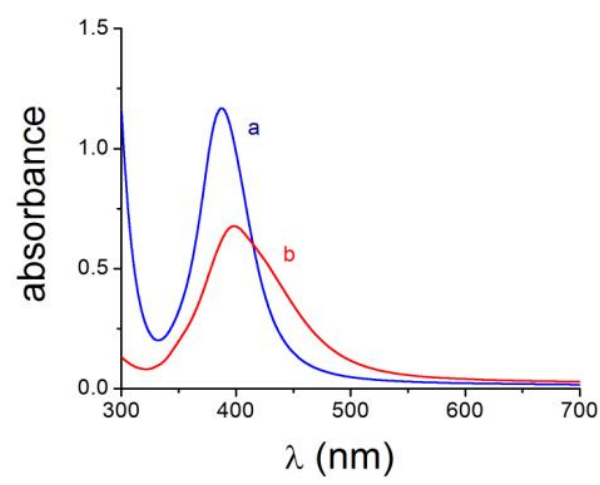

Figure 1. Absorption spectra of silver colloid $\left(1 \times 10^{-4} \mathrm{M} \mathrm{Ag}\right)$ before (a) and after stabilization with $1 \%$ gelatin (b).

The obtained results are in accordance with the literature data (Laban et al., 2014), which show that small spherical Ag NPs possess an intense surface plasmon resonance peak. It is well known that due to collective oscillations of the conduction electrons, known as surface plasmon resonance, metal NPs possess characteristic band in the absorption spectra (Wiley et al., 2006). Position, width, and the number of the absorption bands depend on the nature of the metal, as well as the size and shape of the metal NPs (Liz-Marzán, 2006). Thus, spherical NPs possess one absorption band, while anisotropic NPs possess more than one band in the absorption spectrum (Wiley et al., 2006; Liz-Marzán, 2006). 
The absorption spectra of $\mathrm{Cu}$ NPs are given in Fig. 2 . Copper colloid has absorption band with a maximum at $565 \mathrm{~nm}$, which is in accordance with the previously reported data for spherical copper NPs (Valodkar et al., 2011). However, the presence of gelatin does not have a significant influence on the absorption spectra of $\mathrm{Cu}$ NPs.

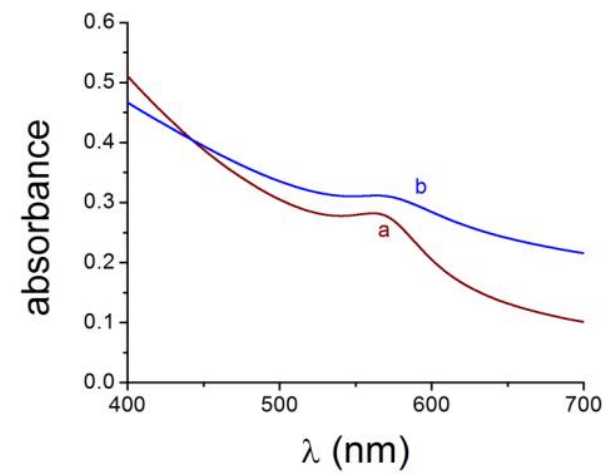

Figure 2. Absorption spectra of copper colloid $\left(4 \times 10^{-4} \mathrm{M} \mathrm{Cu}\right)$ before (a) and after stabilization with $1 \%$ gelatin (b).

\section{AFM measurements}

AFM topography obtained for Ag colloidal dispersion in the absence and presence of gelatin is given in Fig. 3. The samples were prepared by depositing a drop of colloidal solutions on a freshly cleaved mica substrate and left to dry for 1 h.

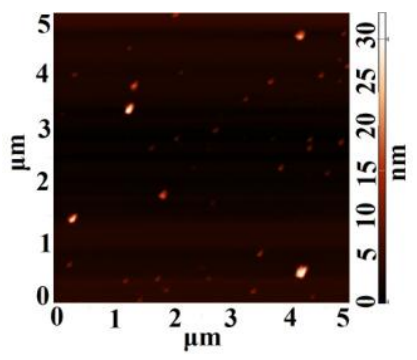

a)

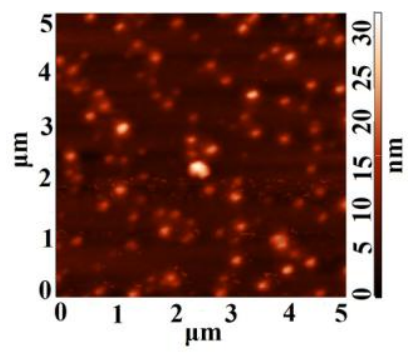

b)
Figure 3. AFM topography of silver nanoparticles without (a) and in presence of gelatin (b).
From AFM topography it can be seen that the particles are of nanometer-size and nearly spherical in shape. The diameter of Ag NPs was determined by measuring the heights of particles above the substrate. The obtained values were $10 \pm 2 \mathrm{~nm}$ for particles from a colloidal dispersion prepared in the presence of ascorbic acid, and $15 \pm 5 \mathrm{~nm}$ for particles from a colloidal dispersion which is additionally stabilized with gelatin. Higher values in size of Ag NPs in presence of gelatin is due to additional shell formed by adsorbed gelatin molecules on the surface of NPs.

AFM topography for $\mathrm{Cu}$ colloidal dispersion is given in Fig. 4. The size of $\mathrm{Cu}$ NPs was determined in the same way as for Ag NPs, and the obtained values were $10 \pm 3 \mathrm{~nm}$ for particles which are not stabilized with gelatin, and $15 \pm 3 \mathrm{~nm}$ for particles additionally stabilized by gelatin. It can be seen that $\mathrm{Cu}$ NPs are nearly spherical, as well as Ag NPs, and also have higher values in size in presence of gelatin.

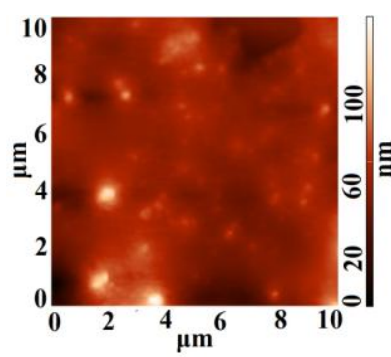

a)

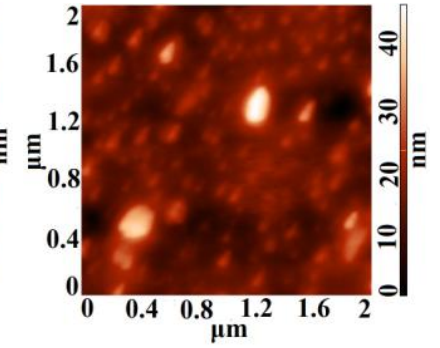

b)
Figure 4. AFM topography of copper nanoparticles without (a) and in presence of gelatin (b).

\section{DLS and zeta potential measurements}

The size of nanoparticles measured by DLS method represents the hydrodynamic diameter of the nanoparticle (Tomaszewska et al., 2013) and the thickness of its electrical double layer has a significant effect on the measured size (Tomaszewska et al., 2013). The obtained values for mean particle size ( $\mathrm{z}$-average- $\mathrm{d}_{\mathrm{av}}$ ) of Ag NPs and Cu NPs before and after gelatin stabilization, together with data obtained from zeta potential, conductivity and mobility measurements are given in Table 1.

Table 1. Mean particle size $\left(\mathrm{d}_{\mathrm{av}}\right)$, zeta potential, conductivity and electrophoretic mobility for Ag and Cu colloids in the absence and presence of gelatin.

\begin{tabular}{|c|c|c|c|c|c|}
\hline & PdI & $\mathrm{d}_{\mathrm{av}}(\mathrm{nm})$ & $\begin{array}{c}\text { Zeta } \\
\text { potential } \\
(\mathrm{mV})\end{array}$ & $\begin{array}{c}\text { Conductivity } \\
\left(\mu \mathrm{S} \mathrm{cm}^{-1}\right)\end{array}$ & Mobility \\
\hline Ag NPs & 0.480 & $56.16 \pm 1.9$ & $-29.5 \pm 6.1$ & $0.087 \pm 0.001$ & $-2.32 \pm 0.47$ \\
Ag NPs-g & 0.358 & $121.5 \pm 3.0$ & $-21.7 \pm 2.9$ & $0.090 \pm 0.001$ & $-1.70 \pm 0.22$ \\
Cu NPs & 0.856 & $49.97 \pm 3.6$ & $-45.0 \pm 1.8$ & $0.812 \pm 0.026$ & $-3.53 \pm 0.14$ \\
Cu NPs-g & 0.767 & $81.67 \pm 3.2$ & $-43.5 \pm 3.4$ & $0.981 \pm 0.028$ & $-3.41 \pm 0.27$ \\
\hline
\end{tabular}


Compared to AFM measurements, the values of $\mathrm{d}_{\mathrm{av}}$ obtained by DLS measurements were higher and included the added solvent and stabilizer moving with the particle. Besides, the addition of gelatin to the colloid dispersions increased the diameter of the particles, as the additional shell of adsorbed gelatin molecules on the $\mathrm{Ag}$ and $\mathrm{Cu}$ NPs surface is present. Although high polydispersity index values, Pdi, (>0.5), were obtained in the case of $\mathrm{Cu}$ NPs, indicating a broad particle size distribution, the mean particle size values (obtained by DLS measurements) were used as relevant for particle size characterization. The zeta potential measurements indicated that $\mathrm{Ag}$ and $\mathrm{Cu}$ NPs are negatively charged, both in the absence and presence of gelatin. As can be seen from Table 1, the conductivity of the colloid dispersions can be changed due to the replacement of capping ions. Also, the electrophoretic mobility of $\mathrm{Ag}$ and $\mathrm{Cu}$ NPs is negative, indicating that the particles acquired a net negative charge.

\section{Antibacterial properties}

Antibacterial activity of all colloidal dispersions was tested against gram-negative bacteria Acinetobacter, Escherichia Coli, Pseudomonas aeruginosa and Klebsiella pneumoniae, and grampositive bacteria Enterococcus faecium. It was found that both in the absence and presence of gelatin, $\mathrm{Ag}$ and $\mathrm{Cu}$ NPs exhibited antibacterial activity against all tested bacteria. This could be explained by the interaction between the outer membrane of bacteria with the released $\mathrm{Au}$ and $\mathrm{Cu}$ ions from a colloidal dispersion or from the surface of NPs. However, a further detailed study is required to clarify the antibacterial performance against tested bacteria, including the investigations on the concentration dependent manner and releasing mechanism of $\mathrm{Ag}$ and $\mathrm{Cu}$ NPs.

\section{CONCLUSION}

In summary, we have synthesized silver and copper nanoparticles at room temperature by chemical reduction method in the presence of ascorbic acid and subsequently stabilized by gelatin. The size of $\mathrm{Ag}$ and $\mathrm{Cu}$ NPs determined by AFM measurements was around $10 \mathrm{~nm}$ in the presence of ascorbic acid and around $15 \mathrm{~nm}$ in presence of gelatin. The zeta potential measurements indicated that these nanoparticles are negatively charged, both in the absence and presence of gelatin. The colloidal dispersion of $\mathrm{Ag}$, as well as of $\mathrm{Cu}$ nanoparticles, exhibited antibacterial activity against gram-negative bacteria Acinetobacter, Escherichia Coli, Pseudomonas aeruginosa and Klebsiella pneumoniae and against gram-positive bacteria Enterococcus faecium.

\section{ACKNOWLEGMENTS}

Authors would like to thank the Ministry of Education and Science of the Republic of Serbia (Project No. 172023) for their financial support. Thank to Dr. Verica Simić, a specialist in microbiology and parasitology, from Public Health Institute of Kosovska Mitrovica, for help in the antibacterial studies.

\section{REFERENCES}

Amendola, V., Bakr, O.M., \& Stellacci, F. 2010. A Study of the Surface Plasmon Resonance of Silver Nanoparticles by the Discrete Dipole Approximation Method: Effect of Shape, Size, Structure, and Assembly. Plasmonics, 5, pp. 85-97.

Austin, L.A., Mackey, M.A., Dreaden, E.C., \& El-Sayed, M.A. 2014. The optical, photothermal, and facile surface chemical properties of gold and silver nanoparticles in biodiagnostics, therapy, and drug delivery. Arch. Toxicol., 88(7), pp. 1391417. pmid:24894431

Chekin, F., \& Ghasemi, S. 2014. Silver nanoparticles prepared in presence of ascorbic acid and gelatin, and their electrocatalytic application. Bulletin of Materials Science, 37, pp. 1433-1437.

Chicea, D. 2014. Using AFM Topography Measurements In Nanoparticle Sizing. Romanian Reports in Physics, 66, pp. 778-787.

Daniel, M., \& Astruc, D. 2004. Gold nanoparticles: Assembly, supramolecular chemistry, quantum-size-related properties, and applications toward biology, catalysis, and nanotechnology. Chem. Rev., 104(1), pp. 293-346. pmid:14719978

Dong, X., Ji, X., Wu, H., Zhao, L., Li, J., \& Yang, W. 2009. Shape Control of Silver Nanoparticles by Stepwise Citrate Reduction. The Journal of Physical Chemistry C, 113, pp. 6573-6576.

Ehsani, A., Jaleh, B., \& Nasrollahzadeh, M. 2014. Electrochemical properties and electrocatalytic activity of conducting polymer/copper nanoparticles supported on reduced graphene oxide composite. Journal of Power Sources, 257, pp. 300-307.

Hoo, C.M., Starostin, N., West, P., \& Mecartney, M.L. 2008. A comparison of atomic force microscopy (AFM) and dynamic light scattering (DLS) methods to characterize nanoparticle size distributions. Journal of Nanoparticle Research, 10(S1), pp. 89-96. doi:10.1007/s11051-008-9435-7

Hu, J.-., Chen, Q., Xie, Z.-., Han, G.-., Wang, R.-., Ren, B., . . . Tian, Z.-. 2004. A Simple and Effective Route for the Synthesis of Crystalline Silver Nanorods and Nanowires. Advanced Functional Materials, 14(2), pp. 183189. doi:10.1002/adfm.200304421

Kelly, K.L., Coronado, E., Zhao, L.L., \& Schatz, G.C. 2003. The Optical Properties of Metal Nanoparticles: The Influence of Size, Shape, and Dielectric Environment. The Journal of Physical Chemistry B, 107, pp. 668-677.

Klapetek, P., Valtr, M., Nečas, D., Salyk, O., \& Dzik, P. 2011. Atomic force microscopy analysis of nanoparticles in nonideal conditions. Nanoscale Research Letters, 6(514).

Laban, B., Vodnik, V., Vujačić, A., Sovilj, S.P., Jokić, A.B., \& Vasić, V. 2013. Spectroscopic and Fluorescence Properties of Silver-Dye Composite Nanoparticles. Russian Journal of Physical Chemistry A, 87, pp. 2219-2224.

Laban, B., Vodnik, V., Dramićanin, M., Novaković, M., Bibić, N., Sovilj, S.P., \& Vasić, V.M. 2014. Mechanism and Kinetics of J-Aggregation of Thiacyanine Dye in the 
Presence of Silver Nanoparticles. The Journal of Physical Chemistry C, 118, pp. 23393-23401.

Laban, B., Vodnik, V., \& Vasić, V. 2015. Spectrophotometric observations of thiacyanine dye J-aggregation on citrate capped silver nanoparticles. Nanospectroscopy, 1, pp. 54-60.

Laban, B., Zeković, I., Vasić Anićijević, D., Marković, M., Vodnik, V., Luce, M., . . V Vasić, V. 2016. Mechanism of 3, 3'-Disulfopropyl-5, 5'-Dichlorothiacyanine Anion Interaction With Citrate-Capped Silver Nanoparticles: Adsorption and JAggregation. The Journal of Physical Chemistry C, 120, pp. 18066-18074.

Lee, Y., Choi, J., Lee, K.J., Stott, N.E., \& Kim, D. 2008. Largescale synthesis of copper nanoparticles by chemically controlled reduction for applications of inkjet-printed electronics. Nanotechnology, 19(41), p. 415604 pmid:21832649. doi:10.1088/0957-4484/19/41/415604

Li, M., Cushing, S.K., \& Wu, N. 2015. Plasmon-enhanced optical sensors: A review. Analyst, 140(2), pp. 386-406. pmid:25365823

Li, Y., Wu, Y., \& Ong, B.S. 2005. Facile synthesis of silver nanoparticles useful for fabrication of high-conductivity elements for printed electronics. J. Am. Chem. Soc., 127(10), pp. 3266-7. pmid:15755129

Liz-Marzán, L.M. 2006. Tailoring surface plasmons through the morphology and assembly of metal nanoparticles. Langmuir , 22(1), pp. 32-41. pmid:16378396

Lu, L.M., Zhang, X.B., Shen, G.L., \& Yu, R.Q. 2012. Seedmediated synthesis of copper nanoparticles on carbon nanotubes and their application in nonenzymatic glucose biosensors. Analytica Chimica Acta, 715, pp. 99-104.

Mahmoud, M.A., Chamanzar, M., Adibi, A., \& El-Sayed, M.A. 2012. Effect of the dielectric constant of the surrounding medium and the substrate on the surface plasmon resonance spectrum and sensitivity factors of highly symmetric systems: Silver nanocubes. J. Am. Chem. Soc., 134(14), pp. 6434-42. pmid:22420824

Maria, K., Susmit, K., Rosaria, B., Simona, P., la Carola, T., Giovanni, B., . . . Athanassia, A. 2013. Electrical response from nanocomposite PDMS-Ag NPs generated by in situ laser ablation in solution. Nanotechnology, 24, p. 35707.

Mogensen, K.B., \& Kneipp, K. 2014. Size-Dependent Shifts of Plasmon Resonance in Silver Nanoparticle Films Using Controlled Dissolution: Monitoring the Onset of Surface Screening Effects. The Journal of Physical Chemistry C, 118, pp. 28075-28083.

Mulvaney, P. 1996. Surface Plasmon Spectroscopy of Nanosized Metal Particles. Langmuir, 12, pp. 788-800.

Panacek, A., Kvítek, L., Prucek, R., Kolar, M., Vecerova, R., Pizúrova, N., . . . Zboril, R. 2006. Silver colloid nanoparticles: Synthesis, characterization, and their antibacterial activity. J Phys Chem B, 110(33), pp. 16248-53. pmid:16913750

Qin, Y., Ji, X., Jing, J., Liu, H., Wu, H., \& Yang, W. 2010. Size control over spherical silver nanoparticles by ascorbic acid reduction. Colloids and Surfaces A: Physicochemical and Engineering Aspects, 372, pp. 172-176.

Ramyadevi, J., Jeyasubramanian, K., Marikani, A., Rajakumar, G., \& Rahuman, A.A. 2012. Synthesis and antimicrobial activity of copper nanoparticles. Materials Letters, 71, pp. 114-116.
Salavati-Niasari, M., \& Davar, F. 2009. Synthesis of copper and copper(I) oxide nanoparticles by thermal decomposition of a new precursor. Materials Letters, 63, pp. 441-443.

Song, J., Kim, H., Jang, Y., \& Jang, J. 2013. Enhanced Antibacterial Activity of Silver/Polyrhodanine-CompositeDecorated Silica Nanoparticles. ACS Applied Materials \& Interfaces, 5, pp. 11563-11568.

Sosa, I.O., Noguez, C., \& Barrera, R.G. 2003. Optical Properties of Metal Nanoparticles with Arbitrary Shapes. The Journal of Physical Chemistry B, 107, pp. 6269-6275.

Tomaszewska, E., Soliwoda, K., Kadziola, K., Tkacz-Szczesna, B., Celichowski, G., Cichomski, M., Szmaja, W. \& Grobelny, J. 2013. Detection Limits of DLS and UV-Vis Spectroscopy in Characterization of Polydisperse Nanoparticles Colloids. Journal of Nanomaterials, pp. 10. doi: 10.1155/2013/313081

Valodkar, M., Modi, S., Pal, A., \& Thakore, S. 2011. Synthesis and anti-bacterial activity of $\mathrm{Cu}, \mathrm{Ag}$ and $\mathrm{Cu}-\mathrm{Ag}$ alloy nanoparticles: A green approach. Materials Research Bulletin, 46, pp. 384-389.

Walcarius, A., Minteer, S.D., Wang, J., Lin, Y., \& Merkoçi, A. 2013. Nanomaterials for bio-functionalized electrodes: Recent trends. Journal of Materials Chemistry B, 1, pp. 48784908.

Wang, F., Widejko, R.G., Yang, Z., Nguyen, K.T., Chen, H., Fernando, L.P., . . . Anker, J.N. 2012. Surface-enhanced raman scattering detection of $\mathrm{pH}$ with silica-encapsulated 4mercaptobenzoic acid-functionalized silver nanoparticles. Anal. Chem., 84(18), pp. 8013-9. pmid:22881392

Wang, H., Huang, Y., Tan, Z., \& Hu, X. 2004. Fabrication and characterization of copper nanoparticle thin-films and the electrocatalytic behavior. Analytica Chimica Acta, 526, pp. 13-17.

Wiley, B.J., Im, S.H., Li, Z., McLellan, J., Siekkinen, A., \& Xia, Y. 2006. Maneuvering the surface plasmon resonance of silver nanostructures through shape-controlled synthesis. J Phys Chem B, 110(32), pp. 15666-75. pmid:16898709

Yacamán, M., Ascencio, J.A., Liu, H.B., \& Gardea-Torresdey, J. 2001. Structure shape and stability of nanometric sized particles. Journal of Vacuum Science \& Technology B: Microelectronics and Nanometer Structures, 19(4), p. 1091. doi:10.1116/1.1387089

Zain, N.M., Stapley, A.G.F., \& Shama, G. 2014. Green synthesis of silver and copper nanoparticles using ascorbic acid and chitosan for antimicrobial applications. Carbohydrate Polymers, 112, pp. 195-202.

Zhang, Q., Li, N., Goebl, J., Lu, Z., \& Yin, Y. 2011. A systematic study of the synthesis of silver nanoplates: Is citrate a "magic" reagent?. J. Am. Chem. Soc., 133(46), pp. 18931-9. pmid:21999679

Zhang, Q., Uchaker, E., Candelaria, S.L., \& Cao, G. 2013. Nanomaterials for energy conversion and storage. Chem Soc Rev, 42(7), pp. 3127-71. pmid:23455759

Zhu, H., Zhang, C., \& Yin, Y. 2005. Novel synthesis of copper nanoparticles: Influence of the synthesis conditions on the particle size. Nanotechnology, 16(12), pp. 3079-3083. doi:10.1088/0957-4484/16/12/059 